\title{
Review:
}

\section{A survey of drag and heat reduction in supersonic flows by a counterflowing jet and its combinations"}

\author{
Wei HUANG \\ (Science and Technology on Scramjet Laboratory, National University of Defense Technology, Changsha 410073, China) \\ E-mail: gladrain2001@163.com \\ Received Jan. 27, 2015; Revision accepted May 14, 2015; Crosschecked June 16, 2015
}

\begin{abstract}
Drag reduction and thermal protection is very important for hypersonic vehicles, and a counterflowing jet and its combinations is one of the most promising drag and heat release reduction strategies. In the current survey, research progress on the drag and heat release reduction induced by a counterflowing jet and its combinations is summarized. Three combinatorial configurations are considered, namely the combination of the counterflowing jet and a forward-facing cavity, the combination of the counterflowing jet and an aerospike, and the combination of the counterflowing jet and energy deposition. In conclusion, some recommendations are provided, especially for jet instability protection, for the tradeoff between drag and heat release reductions, and for the critical points for the operational and geometric parameters in the flow mode transition.
\end{abstract}

Key words: Hypersonic vehicle, Drag reduction, Heat release reduction, Counterflowing jet, Forward-facing cavity, Energy deposition

doi: $10.1631 /$ jzus.A1500021

Document code: A

CLC number: V43

\section{Introduction}

Drag reduction and thermal protection on the surface of a hypersonic vehicle becomes especially important when the vehicle enters the atmosphere at high speed (Ho and Paull, 2006), as shown in Fig. 1 (Pezzella, 2012). Such vehicles include hypervelocity projectiles, reentry vehicles (Ohtake, 1998; Huang et al., 2012b), and hypersonic aircraft (Huang et al., 2011). Fig. 1 shows the heat flux comparison for three typical reentry loading environments. It is clearly shown that the maximum heat flux for the reusable first stage is the lowest, but even that is above $100 \mathrm{~kW} / \mathrm{m}^{2}$. Therefore, damage on the nose of

\footnotetext{
* Project supported by the Science Foundation of National University of Defense Technology (No. JC14-01-01), and a fund for owner of Outstanding Doctoral Dissertation from the Ministry of Education of China (No. 201460)

(D) ORCID: Wei HUANG, http://orcid.org/0000-0001-9805-985X

(C) Zhejiang University and Springer-Verlag Berlin Heidelberg 2015
}

the vehicle induced by high temperature and high pressure must be prevented.

The wave drag force is more than half of the total drag force when the vehicle flies at hypersonic speed, and increases sharply with increasing freestream Mach number. Therefore, the overall drag reduction is focused on the reduction of the wave drag force (Bushnell, 2004). At the same time, the maximum heat flux usually occurs at the stagnation point of the nose of the vehicle, and it has a strong relationship with the value of the wave drag force. Therefore, most attention should be paid to the physical parameter distributions of the nose, i.e., the wall static pressure and the heat flux.

Recently, many techniques, for example, concentrated energy deposition along the stagnation streamline, a retractable aerospike ahead of the blunt body, and a counterflowing jet in the stagnation zone of the blunt body (Gerdroodbary and Hosseinalipour, 2010), have been proposed to reduce the drag and heat release, and they can be categorized into passive 
and active approaches according as to whether the method can be controlled or not. The passive approach is the retractable aerospike installed ahead of the blunt body employed to reduce the intensity of the shock wave. Ahmed and Qin (2011) provided a detailed review on the spiked hypersonic vehicle, and they also pointed out that some areas in this field need further investigation. Active approaches are energy deposition along the stagnation streamline and a counterflowing jet in the stagnation zone of the blunt body. Because of the difficulty of its engineering implementation, the investigation of the energy deposition method has remained a theoretical one. Knight (2008) has reviewed the research on the aerodynamic drag reduction induced by energy deposition. In the counterflowing jet flow field, small scale vortical structures mainly occur in the jet column, and the large scale vortices develop gradually in a recirculation zone when the jet terminates through a Mach disk and reverses its orientation as a conical free shear layer. The recirculation zone ahead of the blunt body has a great impact on heat flux reduction, and on reduction of the drag force.

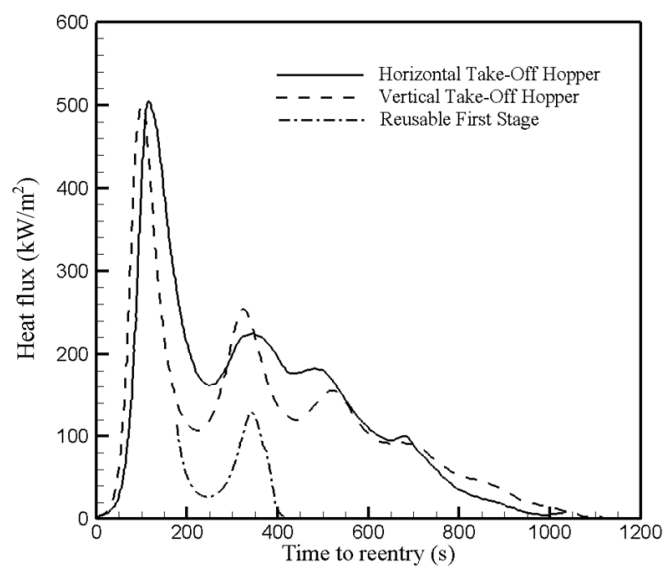

Fig. 1 Heat flux comparison for three typical reentry loading environments. Reprinted from (Pezzella, 2012), Copyright 2012, with permission from Elsevier Masson SAS

To the best of the author's knowledge, research on the drag and heat release reduction induced by a counterflowing jet and its combinations has not been summarized in the open literature, and it is very important to explore the information in its drag and heat release reduction mechanism. As is well known, there are many influencing factors in the transverse injection flow field (Karagozian, 2010; Huang and Yan, 2013), namely the operational and geometric parameters, and variation of these parameters will result in some reduction in the drag force and heat flux as well.

In the current survey, progress in research on a counterflowing jet and its combinations has been reviewed. These combinations include the combination of the counterflowing jet and an aerospike, the combination of the counterflowing jet and energy deposition, and the combination of the counterflowing jet and a forward-facing cavity. Finally, some recommendations on the areas requiring urgent investigation have been made.

\section{Counterflowing jet}

The flowfield around a blunt body with a counterflowing jet was categorized by Finley (1966) into three conditions, namely steady, unsteady, and transitional, and these are the same as are observed around a blunt body with an aerospike (Feszty et al., 2004; Panaras and Drikakis, 2009). Venukumar et al. (2006) conducted an experiment on the drag force reduction induced by a counterflowing jet, and a reduction of about $45 \%$ was possible for larger values of the jet pressure ratio (Fig. 2). In their study, the jet pressure ratio (PR) is defined as the ratio of the jet total pressure to the pitot pressure of the test flow, namely,

$$
\mathrm{PR}=P_{0 \mathrm{j}} / P_{0 \infty},
$$

where $P_{0 \mathrm{j}}$ and $P_{0 \infty}$ are the total pressures of the jet and the test flow, respectively.

However, they only considered steady flow fields with jet pressure ratios much larger than the critical value, which is 6.5 when the freestream Mach number is 8.0 . The static pressure is $220 \mathrm{~Pa}$ and the static temperature is $150 \mathrm{~K}$. The critical value of the jet pressure ratio is employed to categorise the counterflowing jet flow fields, and the counterflowing jet flow field is steady when the jet pressure ratio is larger than that critical value. Further, the freestream enthalpy has a great impact on the drag force reduction as well, and the drag force reduction 
increases with the increase in stagnation enthalpy (Fig. 3) (Kulkarni and Reddy, 2008). However, the physical mechanism is still not clear, in particular how the freestream enthalpy affects the drag force is not fully understood and it needs to be explored further. At the same time, the jet stagnation temperature has proved to be important in drag force reduction (Ganiev et al., 2000), and the drag force reduction value varies with it. The influence of the total pressure ratio on the heat release reduction of a blunt body with counterflowing jets has been analyzed experimentally by Hayashi et al. (2006), and the total pressure ratio is defined as the ratio of the jet total pressure to the freestream total pressure. In their experiments, steady and unsteady conditions are both

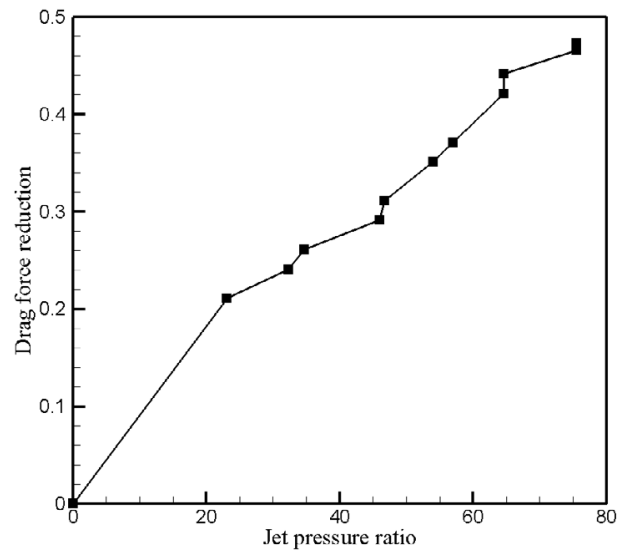

Fig. 2 Drag force reduction for different jet pressure ratios of the Mach 8 test flow. Reprinted from (Venukumar et al., 2006), Copyright 2006, with permission from AIP Publishing LLC

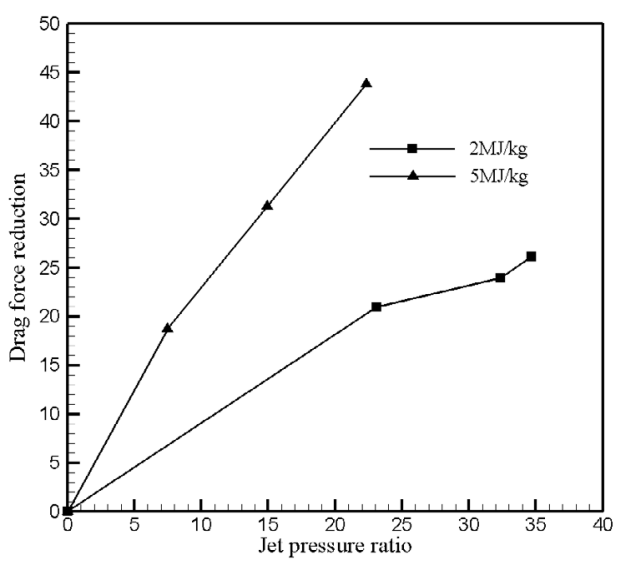

Fig. 3 Comparison of drag force reduction for Mach 8 flow with different freestream enthalpies. Reprinted from (Kulkarni and Reddy, 2008), Copyright 2008, with permission from AIP Publishing LLC taken into consideration. The results obtained show that the unsteady condition has no visible impact on the heat release reduction, but the heat release reduction increases with the increase of the total pressure ratio at the steady condition. Li and Eri (2007) and Wang Z.Q. et al. (2010) have analyzed numerically the influences of the pressure ratio and the counterflowing nozzle diameter ratio on the aerodynamic heating reduction.

The heat release reduction of a blunt body with micro-jets has been investigated experimentally by Sriram and Jagadeesh (2009) with effective area kept constant. Their experiments have been performed at freestream Mach number 5.9 with a stagnation enthalpy of $1.84 \mathrm{MJ} / \mathrm{kg}$. The obtained results show that the cooling performance of an array of closely spaced micro-jets is much better than that of a corresponding single jet over nearly all the whole surface, and a heavier injection gas gives a better cooling performance. This phenomenon is the same as the effect of molecular weight on the mixing improvement in transverse injection flow fields (Huang et al., 2014a). Venukumar and Reddy (2007) have conducted experiments on the effect of the injection species on aerodynamic drag reduction; however, the overall drag force reduction performance has not been compared. That is to say that the influence of injection species on the drag force reduction has not been evaluated quantitatively and a maximum of $29 \%$ reduction in the drag coefficient has been obtained with a supersonic counterflowing jet.

The drag force reductions on the blunt cone flare and large blunt cone flare bodies with a counterflowing jet have been studied numerically by Aruna and Anjalidevi (2012); the counterflowing jet is found to be very effective for the reduction of pressure drag, skin friction drag, and total drag force. Meyer et al. (2001), Tian and Yan (2008), and Wang $\mathrm{X}$. et al. (2010) have also validated the drag force reduction mechanism of the counterflowing jet numerically. At the same time, the minimum counterflowing jet ejection has been successfully employed in an Apollo command module (Zheng et al., 2012). $\mathrm{Lu}$ and Liu (2012a) have investigated numerically the influence of the angle of attack on a hemisphere nose-tip with a counterflowing jet and they found that the cruise angle of attack has a great impact on the flow field parameters (Huang and Wang, 2009), 
aerodynamic force, and surface heat flux distribution, and that the parameter distributions were asymmetric. A new parameter $R_{\mathrm{PA}}$ was proposed by Rong and Liu (2010) and Rong (2013) to analyze the influence of a counterflowing jet on flow field properties as well as on the aerodynamic force of the blunt body, and it has been shown to depend on the intensity of the counterflowing jet. Its definition is as follows:

$$
R_{\mathrm{PA}}=\frac{P_{0 \mathrm{j}}}{P_{0 \infty}} \frac{A_{\mathrm{j}}}{A_{\text {base }}}=\frac{P_{0 \mathrm{j}}}{P_{0 \infty}} \frac{R_{\mathrm{j}}^{2}}{R^{2}},
$$

where $R_{\mathrm{j}}$ is the radius of the jet exit, and $R$ is the radius of the blunt body. $A_{\mathrm{j}}$ and $A_{\text {base }}$ are the areas of the jet orifice exit and the base plane of the blunt body, respectively.

Zhou and Ji (2014) have investigated numerically the influences of the jet pressure, the nozzle size of the jet, and the angle of attack on the drag force reduction of a spherical body with a sonic counterflowing jet from its stagnation point. The freestream Mach number was set to be 2.5. In their research, a critical jet pressure ratio $\left(P_{\text {crit }}\right)$ was obtained as well, and it varies approximately linearly with the jet nozzle exit size (Fig. 4). In Fig. 4, $D$ is the diameter of the jet nozzle exit in millimeters. The jet pressure ratio is as defined by Venukumar et al. (2006). A flow mode transition occurs at this critical point, from an unsteady oscillatory motion mode to a nearly steady motion mode (Fig. 5). The maximum overall drag reduction usually happens at the unsteady oscillatory motion mode. This conclusion is consistent with that obtained with plasma injection by Fomin et al. (2002), but the flow field properties induced by the plasma injection and the hot-gas injection are different (Ganiev et al., 2000). This may imply that the variation tendency of the drag reduction is not consistent with that of the heat release reduction, and that there must be a tradeoff in the design of the thermal protection system. The multiobjective design optimization (MDO) approach, as well as the data mining method (Huang et al., 2010; 2012a), is suitable to solve this problem, and it has already been applied successfully to the blunt body with aerospike (Ahmed and Qin, 2010; 2012), as well as to the transverse injection flow field (Huang, 2014; Huang et al., 2014b), supersonic nozzle (Huang et al., 2013a), and cavity flameholder

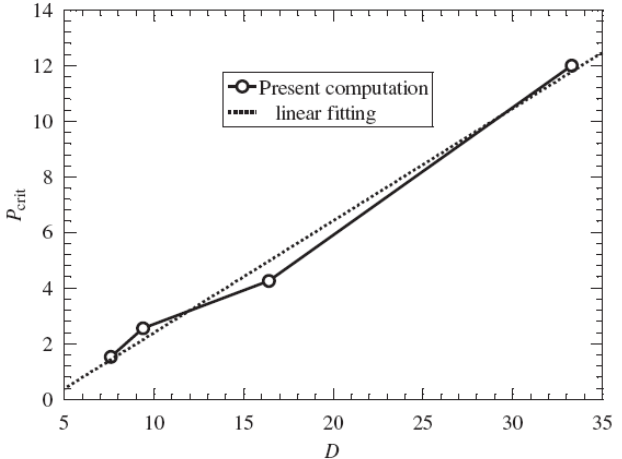

Fig. 4 Variation of critical jet pressure ratio with the jet nozzle exit size. $D$ is in millimeter. Reprinted from (Zhou and $\mathrm{Ji}, 2014$ ), Copyright 2014, with permission from SAGE Publications
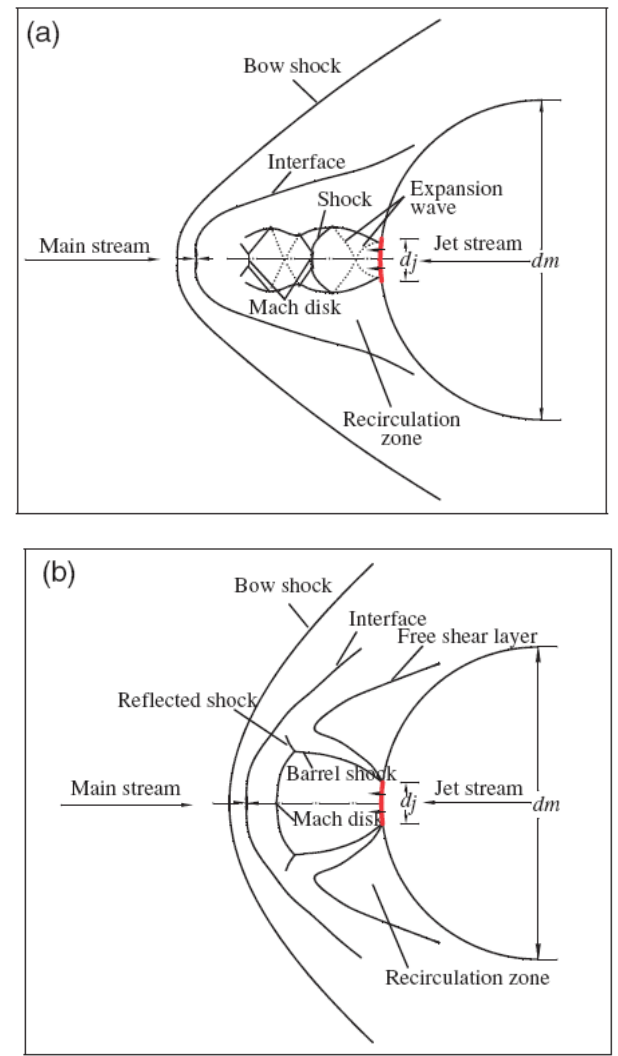

Fig. 5 Flow field properties around the spherical body with counterflowing jet: (a) unsteady state mode with regular reflection; (b) steady-state mode with Mach reflection. Reprinted from (Zhou and Ji, 2014), Copyright 2014, with permission from SAGE Publications

(Huang et al., 2013b). In plasma injection, the drag force reduction is mostly induced by the viscousinviscid interaction of the counterflowing jet and thermal energy deposition (Shang, 2002; Shang et al., 
2002). The flow mode transition is similar to that described by He et al. (2006), Gerdroodbary et al. (2012), and Zhou et al. (2012), namely the unsteady oscillatory and nearly steady motion modes are the long and short penetration modes, respectively (Fig. 6). In the long penetration mode, the bow shock becomes diffused or dispersed, and it is no longer visible. The short penetration mode is shown to be beneficial to heat release reduction (Daso et al., 2009). The short penetration mode jet provides a greater than $15 \%$ reduction in drag force in a Mach 2.0 freestream (Daso et al., 2002). At the same time, a sharp variation in the drag coefficient ratio near the critical point appears (Fig. 7) (Zhou and Ji, 2014), and the sharp variation phenomenon disappears with the increase of the angle of attack (Zhou et al., 2013). In Fig. 7, D is the ratio of the diameter of the jet orifice to that of the blunt body, and $P$ is the jet pressure ratio as PR mentioned above. Chen et al. (2011) have analyzed the detailed flow field structures at the unstable and stable conditions systematically by using a large eddy simulation, and the fundamental mechanisms including shock-wave/jet interaction, shock-wave/shear-layer interaction, turbulent shear-layer evolution, and coherent structures have been studied.

\section{Combination of counterflowing jet and other techniques}

Recently, several novel combinatorial strategies between the counterflowing jet and other techniques have been proposed, and research on the combinatorial strategies for the drag and heat release reductions is described in this section, including the combination of a counterflowing jet and forward-facing cavity, the combination of a counterflowing jet and energy deposition, and the combination of a counterflowing jet and an aerospike.

\subsection{Combination of counterflowing jet and forward-facing cavity}

The influence of a forward-facing cavity on heat transfer and aerodynamic coefficients has been investigated by Saravanan et al. (2009), and the deepest cavity shows better heat flux reduction (Silton and Goldstein, 2005; Lu and Liu, 2012b; Yadav and Guven, 2014). The mechanism of heat reduction induced by a forward-facing cavity has been (a)

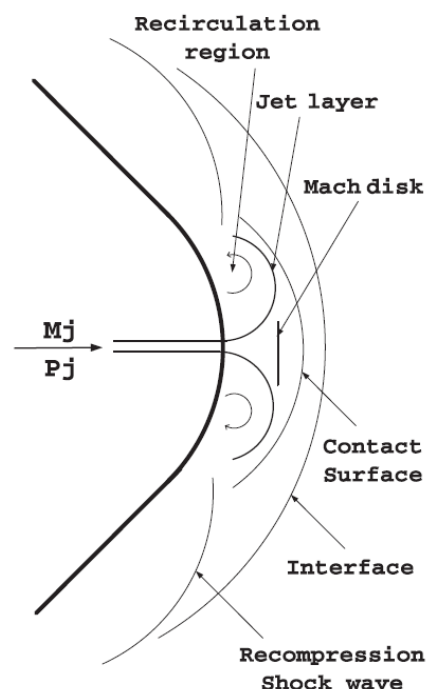

(b)

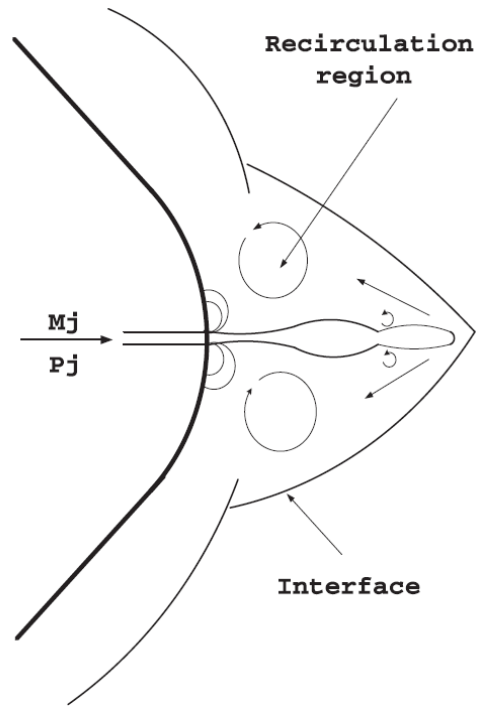

Fig. 6 Comparison of flow field properties around the blunt body with a counterflowing jet: (a) short penetration mode (SPM) jet; (b) long penetration mode (LPM) jet. Reprinted from (Gerdroodbary et al., 2012), Copyright 2012, with permission from Elsevier Masson SAS

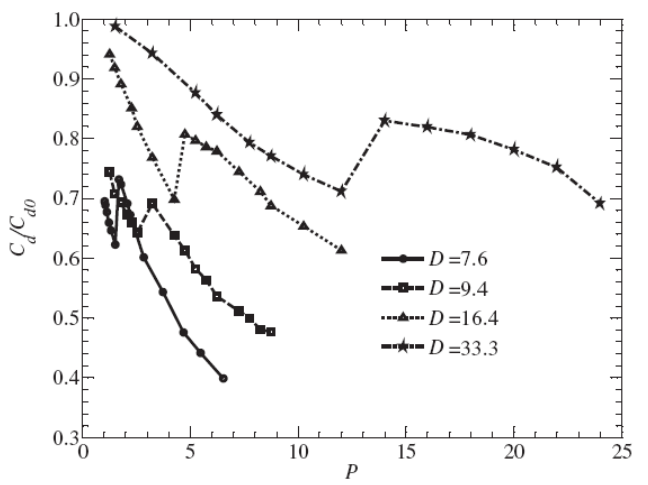

Fig. 7 Variation of drag coefficient ratio with jet pressure ratio under different jet nozzle exit sizes. Reprinted from (Zhou and Ji, 2014), Copyright 2014, with permission from SAGE Publications 
explained by many researchers (Huebner and Utreja, 1993; Engblom et al., 1997), and the cooling effect is produced by the oscillation of the bow shock wave (Ladoon et al., 1998). Thus, the combinatorial configuration with counterflowing jet and forwardfacing cavity (Fig. 8, from (Lu and Liu, 2014)) may be a promising drag and heat release reduction strategy, and it is attracting increasing attention. In Fig. 8, $L$ and $D$ stand for the length and depth of the forward-facing cavity, respectively, and $D_{\mathrm{n}}$ is the diameter of the base surface for the reentry body.

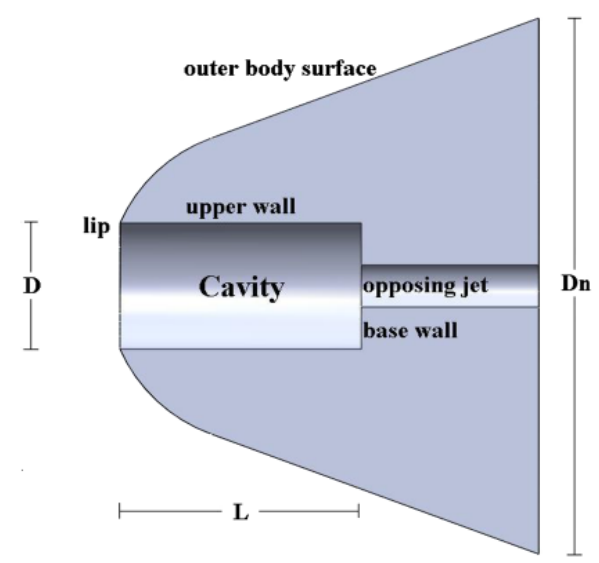

Fig. 8 Schematic diagram of the combination of counterflowing jet and forward-facing cavity. Reprinted from (Lu and Liu, 2014), Copyright 2014, with permission from Springer Science+Business Media

The combinatorial configuration of a counterflowing jet and a forward-facing cavity is more advantageous than that with the counterflowing jet alone when the stagnation pressure of the counterflowing jet is high enough (Huang et al., 2015); its physical mechanism has been provided by $\mathrm{Lu}$ and Liu (2014). When the total pressure ratio is high, namely 0.4 in (Lu and Liu, 2014), the cavity acts just like a speed-up nozzle for the counterflowing jet. The high total pressure ratio is beneficial for performance improvement of the drag and heat release reduction, and the recirculation zone plays an important role in heat release reduction ( $\mathrm{Lu}$ and $\mathrm{Liu}$, 2012c; 2013). However, when the total pressure ratio is low, namely 0.2 in ( $\mathrm{Lu}$ and Liu, 2014), the cavity will waste the energy of the counterflowing jet, and this condition may be unstable (Hayashi et al., 2006). The combinatorial configuration with a low total pressure ratio can avoid the disadvantage induced by the unsteady oscillation in the supersonic cavity flow ( $\mathrm{Lu}$ and Liu, 2012d), and the heat release reduction is more sensitive to the variation of the cavity diameter than to the cavity length ( $\mathrm{Lu}$ and Liu, 2012e). Further information needs to be obtained using unsteady numerical approaches.

\subsection{Combination of counterflowing jet and ener- gy deposition}

Due to the difficulty encountered in the engineering implementation of energy deposition and the instability problem encountered in the counterflowing jet, Khamooshi et al. (2007) have combined the counterflowing jet and the upstream energy deposition at the nose of the blunt body (Fig. 9), and this combinatorial configuration shows larger decreases in overall drag and heat release than the single strategies of a counterflowing jet and energy deposition (Table 1). In Table 1, $\Delta$ stands for the shock standoff distance. $\mathrm{RD}$ is the drag reduction factor, defined as the modified drag value divided by the baseline. RQ is the heat transfer reduction factor, defined as the flowfield modified heat transfer over the baseline. At the same time, the instability problem of the counterflowing jet is significantly reduced by the combinatorial configuration.

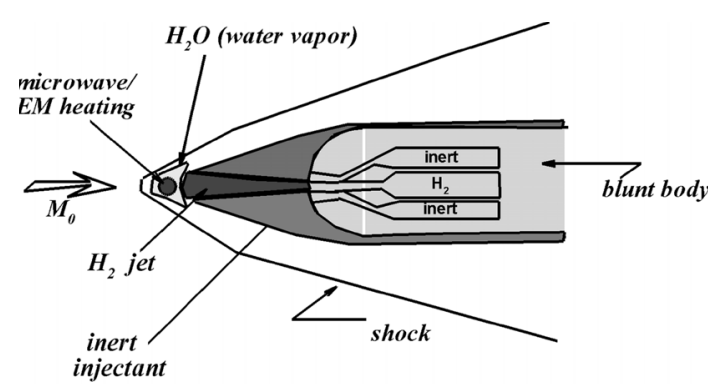

Fig. 9 Schematic diagram of the combination between counterflowing jet and energy deposition. Reprinted from (Khamooshi et al., 2007), Copyright 2007, with permission from AIAA

Table 1 Performance summary of counterflowing jet and energy deposition. Reprinted from (Khamooshi et al., 2007), Copyright 2007, with permission from AIAA

\begin{tabular}{lccc}
\hline \multicolumn{1}{c}{ Item } & $\Delta$ & $\mathrm{RD}$ & $\mathrm{RQ}$ \\
\hline Baseline & 0.16 & 1.00 & 1.00 \\
Counterflowing jet & 0.23 & 0.92 & 0.95 \\
Energy deposition & 0.48 & 0.60 & 1.10 \\
Combinatorial configuration & 1.10 & 0.34 & 0.37 \\
\hline
\end{tabular}


Marley and Riggins (2011) have extended the above work numerically by analyzing the influence of an axisymmetric annular ring injector as well as imposing swirl on the jet stability. The upstream energy deposition is shown to significantly enhance stability and penetration of the counterflowing jet. The annular ring injection exhibits a stabilizing effect on the jet; centered forward injection without upstream energy deposition would encounter high instability.

\subsection{Combination of counterflowing jet and aerospike}

The aerospike is a relatively mature strategy for drag and heat release reductions, and it has already been utilized successfully in some actual vehicles. However, it also has some inherent disadvantages. Firstly, the nose of the aerospike encounters serious local high temperature due to its small radius of curvature (Mehta, 2000). Secondly, the surface heat flux at the shoulder of the blunt body rises abruptly due to the strong shock-wave/shock-wave and shock-wave/boundary-layer interactions. Thirdly, the aerospike induced conical shock wave may hit the body nose or aerospike at relative high angle of attack, and this could result in a local high heat flux area (Lawrence et al., 1995; Gnemmi et al., 2003). Therefore, the combination of aerospike and counterflowing jet has been proposed to solve these problems.

A new adaptive drag reduction and non-ablative thermal protection approach named telescopic selfaligning jet-spike (TSAJS) has been proposed by Geng et al. (2012) (Fig. 10). The influences of the $L / D$ ratio (the ratio of spike length to the cylinder diameter), the freestream and jet Mach numbers, the angle of attack on the flow field structures, and the pressure and heat flux distributions on nose surface have been analyzed. The results obtained show that the TSAJS approach is suitable even for conditions with large angles of attack, and the drag force coefficient and maximum surface heat flux decrease by $65 \%$ when the $L / D$ ratio is 1.0 . At the same time, its drag and heat release reduction efficiencies are both better than those of the case with only counterflowing jets (Geng and Yan, 2010).

Liu and Jiang (2013) have proposed and validated a combinatorial strategy using both aerospike and lateral jets (Fig. 11). In Fig.11, $M$ stands for the freestream Mach number. The lateral jets are used to push the conical leading shock wave away from the blunt body (Jiang et al., 2009), as shown in Fig. 12 (Liu and Jiang, 2013). This can achieve efficient cooling of the aerospike tip, as well as high temperature reduction at the shoulder of the blunt body. The results obtained show that the peak pressure at the reattachment region can be decreased by $65 \%$ even under a $4^{\circ}$ angle of attack by the lateral jet, as shown in Fig. 13 (Liu and Jiang, 2013), and its engineering application appears to be quite promising. In Fig. 13, the symbol $\alpha$ stands for the angle of attack, and $P$ is the wall static pressure. $s / D$ stands for the ratio of the arc length along the blunt body surface measured from the geometric stagnation point to the blunt body diameter.

Gerdroodbary et al. (2014) have proposed a novel strategy to reduce further the aerodynamic drag and the heating rates in the vicinity of the nose tip region of a hypersonic vehicle. A coolant is

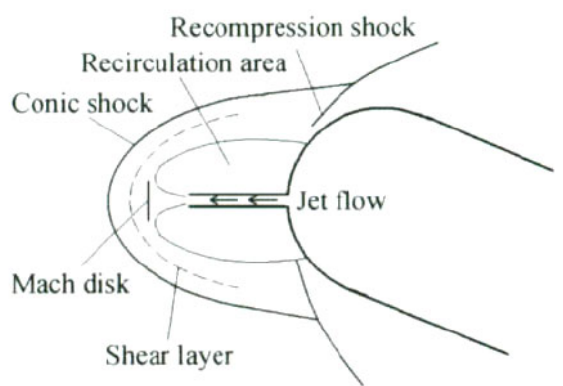

Fig. 10 Schematic diagram of the telescopic self-aligning jet-spike (TSAJS) flow field structure. Reprinted from (Geng et al., 2012), Copyright 2012, with permission from CNKI

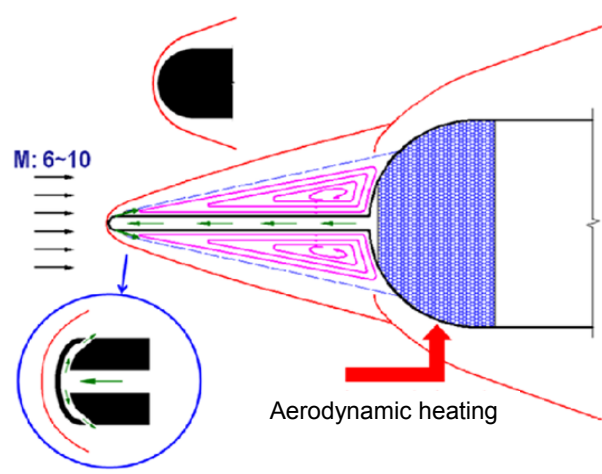

Fig. 11 Operating principles of non-ablative thermal protection system for aerodynamic force and heat load reduction. Reprinted from (Liu and Jiang, 2013), Copyright 2013, with permission from AIAA 
injected from the nose cone behind the aerodisk (Fig. 14, from (Gerdroodbary et al., 2014)). In their study, two different jets, namely helium and carbon dioxide, as well as variations of the jet pressure ratio and spike length have been considered. The results obtained show that the combination of the counterflowing jet and aerospike has a great impact on the heating rate reduction (Fig. 15, from (Gerdroodbary et al., 2014)), and the discrepancy between the performance of the coolant jet with aerospike and that without aerospike decreases with the increase of the pressure ratio.

(a)

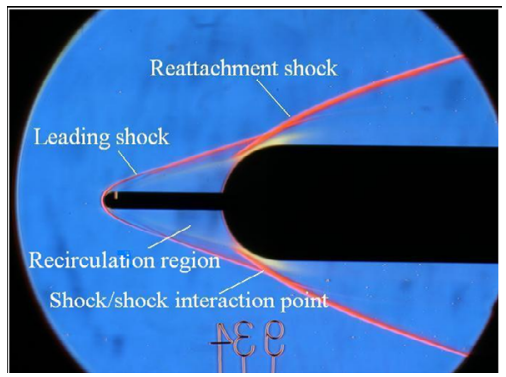

(b)

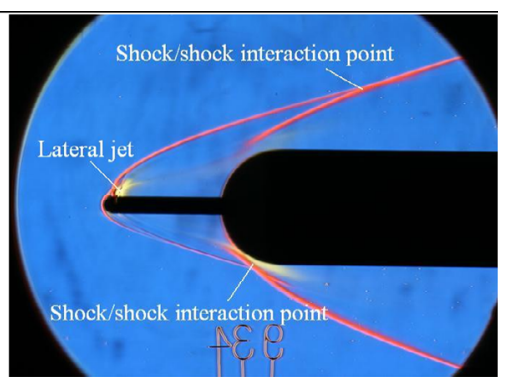

Fig. 12 Comparison of flow field properties around a non-ablative thermal protection system test model with angle of attack being $0^{\circ}$ without lateral jet (a) and with lateral jet (b). Reprinted from (Liu and Jiang, 2013), Copyright 2013, with permission from AIAA

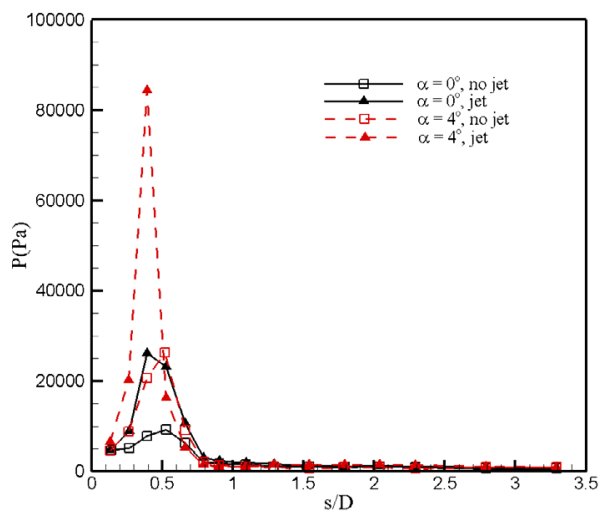

Fig. 13 Wall pressure comparison along the generatrix of non-ablative thermal protection system test model. Reprinted from (Liu and Jiang, 2013), Copyright 2013, with permission from AIAA

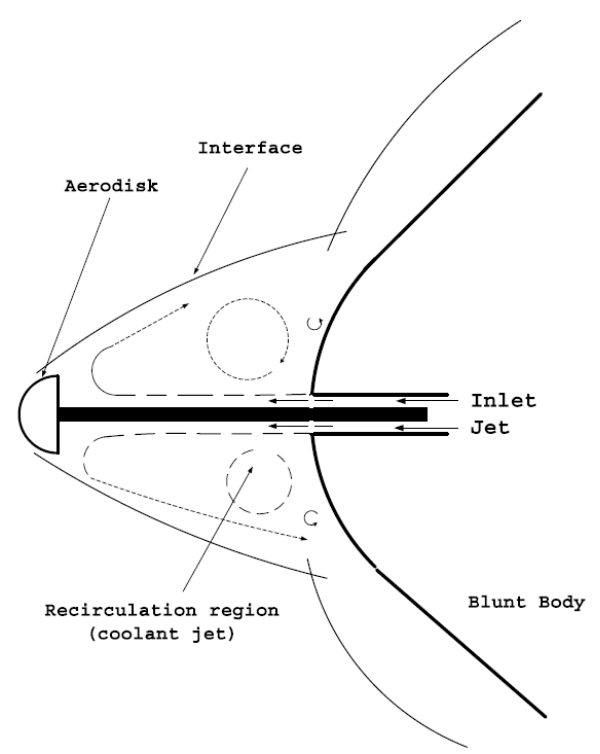

Fig. 14 Schematic diagram of the flow field properties around the aerodisked blunt cone with counterflowing jets. Reprinted from (Gerdroodbary et al., 2014), Copyright 2014, with permission from Elsevier Masson SAS

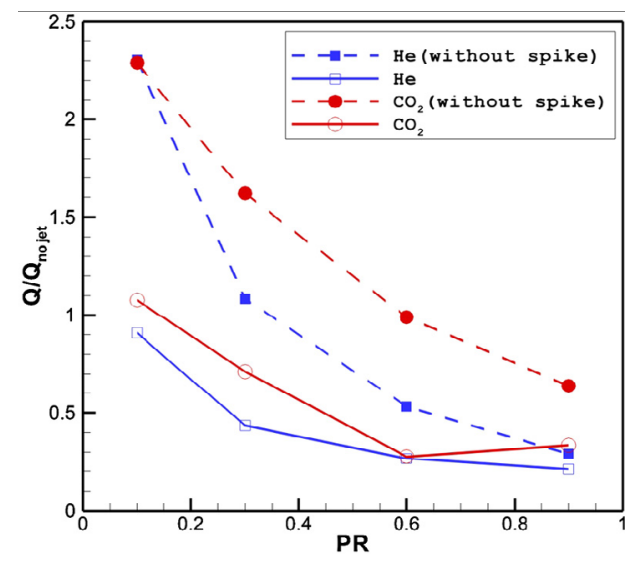

Fig. 15 Comparison of influences of various jet pressure ratios on the heat load reduction of the counterflowing jet with $L / D=1.0$. Reprinted from (Gerdroodbary et al., 2014), Copyright 2014, with permission from Elsevier Masson SAS

\section{Remarks and recommendations}

In this survey, research on the drag and heat release reduction induced by a counterflowing jet and its combinations has been reviewed. Three combinatorial configurations have been considered in the current survey, namely the combination of the counterflowing jet and a forward-facing cavity, the combination of the counterflowing jet and an aerospike, and 
the combination of the counterflowing jet and energy deposition. We came to the following conclusions:

1. The jet instability encountered in a counterflowing jet and its combinations is a critical problem for the variation of drag force, and it needs to be further investigated by using an unsteady numerical approach, especially for the combination of the counterflowing jet and a forward-facing cavity. This would provide a valid supplement for the phenomena observed in the ground experimental test.

2. Drag and heat release reductions on hypersonic vehicles are often conflicting, and they should be solved by using a multi-objective design optimization approach. At the same time, the influences of the operational and geometric parameters on the drag and heat release reductions should be investigated comprehensively, and the critical points for more parameters during the flow mode transition could be obtained. This information would be very useful for the design of a thermal protection system.

3 . The combinatorial configurations show better drag and heat release reduction performance than for a single counterflowing jet, and more attention should be paid to combinations of the counterflowing jet and other techniques. In the flow field around the combinatorial configurations, the local high heat flux at the shoulder of the blunt body disappears, and the recirculation zone increases. Further, the flow rate of the counterflow jet for a real vehicle should be estimated, and it is a crucial step towards an engineering implementation.

\section{References}

Ahmed, M.Y.M., Qin, N., 2010. Metamodels for aerothermodynamic design optimization of hypersonic spiked blunt bodies. Aerospace Science and Technology, 14(5):364376. [doi:10.1016/j.ast.2010.03.003]

Ahmed, M.Y.M., Qin, N., 2011. Recent advances in the aerothermodynamics of spiked hypersonic vehicles. Progress in Aerospace Sciences, 47(6):425-449. [doi:10.1016/j. paerosci.2011.06.001]

Ahmed, M.Y.M., Qin, N., 2012. Surrogate-based multiobjective aerothermodynamic design optimization of hypersonic spiked bodies. AIAA Journal, 50(4):797-810. [doi:10.2514/1.J051018]

Aruna, S., Anjalidevi, S.P., 2012. Computational study on the influence of jet on reduction of drag over cone flare bodies in hypersonic turbulent flow. Procedia Engineering, 38:3635-3648. [doi:10.1016/j.proeng.2012.06.420]

Bushnell, D.M., 2004. Shock wave drag reduction. Annual Review of Fluid Mechanics, 36(1):81-96. [doi:10.1146/ annurev.fluid.36.050802.122110]
Chen, L.W., Wang, G.L., Lu, X.Y., 2011. Numerical investigation of a jet from a blunt body opposing a supersonic flow. Journal of Fluid Mechanics, 684:85110. [doi:10.1017/jfm.2011.276]

Daso, E.O., Beaulieu, W., Hager, J.O., 2002. Prediction of drag reduction in supersonic and hypersonic flows with counter-flow jets. AIAA Paper 2002-5115.

Daso, E.O., Pritchett, V.E., Wang, T.S., et al., 2009. Dynamics of shock dispersion and interactions in supersonic freestreams with counterflowing jets. AIAA Journal, 47(6):1313-1326. [doi:10.2514/1.30084]

Engblom, W.A., Goldstein, D.B., Ladoon, D., et al., 1997. Fluid dynamics of hypersonic forward-facing cavity flow. Journal of Spacecraft and Rockets, 33(3):353-359. [doi:10.2514/3.26767]

Feszty, D., Badcock, K.J., Richards, B.E., 2004. Driving mechanisms of high-speed unsteady spiked body flows, Part 1: pulsation mode. AIAA Journal, 42(1):95-106. [doi:10.2514/1.9034]

Finley, P.J., 1966. The flow of a jet from a body opposing a supersonic free stream. Journal of Fluid Mechanics, 26:337-368. [doi:10.1017/S0022112066001277]

Fomin, V.M., Maslov, A.A., Malmuth, N.D., et al., 2002. Influence of a counterflow plasma jet on supersonic blunt-body pressures. AIAA Journal, 40(6):1170-1177. [doi:10.2514/3.15178]

Ganiev, Y.C., Gordeev, V.P., Krasilnikov, A.V., et al., 2000. Aerodynamic drag reduction by plasma and hot-gas injection. Journal of Thermophysics and Heat Transfer, 14(1):10-17. [doi:10.2514/2.6504]

Geng, Y.F., Yan, C., 2010. Numerical investigation on drag and heat-transfer reduction using combined spike and forward facing jet method. Acta Aerodynamica Sinica, 28(4):436-440 (in Chinese).

Geng, Y.F., Yu, J., Kong, W.X., 2012. Investigation on a new method of adaptive drag reduction and non-ablation thermal protection system for hypersonic vehicles. Acta Aerodynamica Sinica, 30(4):492-501 (in Chinese).

Gerdroodbary, M.B., Hosseinalipour, S.M., 2010. Numerical simulation of hypersonic flow over highly blunted cones with spike. Acta Astronautica, 67(1-2):180-193. [doi:10. 1016/j.actaastro.2010.01.026]

Gerdroodbary, M.B., Bishehsari, S., Hosseinalipour, S.M., et al., 2012. Transient analysis of counterflowing jet over highly blunt cone in hypersonic flow. Acta Astronautica, 73:38-48. [doi:10.1016/j.actaastro.2011.12.011]

Gerdroodbary, M.B., Imani, M., Ganji, D.D., 2014. Heat reduction using counterflowing jet for a nose cone with aerodisk in hypersonic flow. Aerospace Science and Technology, 39:652-665. [doi:10.1016/j.ast.2014.07.005]

Gnemmi, P., Srulijes, J., Roussel, K., et al., 2003. Flowfield around spike-tipped bodies for high attack angles at Mach 4.5. Journal of Spacecraft and Rockets, 40(5): 622-631. [doi:10.2514/2.6910]

Hayashi, K., Aso, S., Tani, Y., 2006. Experimental study on thermal protection system by opposing jet in supersonic flow. Journal of Spacecraft and Rockets, 43(1):233-235. [doi:10.2514/1.15332] 
He, K., Chen, J.Q., Dong, W.Z., 2006. Penetration mode and drag reduction research in hypersonic flows using a counter-flow jet. Chinese Journal of Theoretical and Applied Mechanics, 38(4):438-445 (in Chinese).

Ho, S.Y., Paull, A., 2006. Coupled thermal, structural and vibrational analysis of a hypersonic engine for flight test. Aerospace Science and Technology, 10(5):420-426. [doi:10.1016/j.ast.2006.03.004]

Huang, W., 2014. Design exploration of three-dimensional transverse jet in a supersonic crossflow based on data mining and multi-objective design optimization approaches. International Journal of Hydrogen Energy, 39: 3914-3925. [doi:10.1016/j.ijhydene.2013.12.129]

Huang, W., Wang, Z.G., 2009. Numerical study of attack angle characteristics for integrated hypersonic vehicle. Applied Mathematics and Mechanics (English Edition), 30(6):779-786. [doi:10.1007/s10483-009-0612-y]

Huang, W., Yan, L., 2013. Progress in research on mixing techniques for transverse injection flow fields in supersonic crossflows. Journal of Zhejiang UniversitySCIENCE A (Applied Physics \& Engineering), 14(8): 554-564. [doi:10.1631/jzus.A1300096]

Huang, W., Luo, S.B., Liu, J., et al., 2010. Effect of cavity flame holder configuration on combustion flow field performance of integrated hypersonic vehicle. Science China Technological Sciences, 53(10):2725-2733. [doi:10.1007/s11431-010-4062-9]

Huang, W., Wang, Z.G., Jin, L., et al., 2011. Effect of cavity location on combustion flow field of integrated hypersonic vehicle in near space. Journal of Visualization, 14(4):339-351. [doi:10.1007/s12650-011-0100-3]

Huang, W., Pourkashanian, M., Ma, L., et al., 2012a. Effect of geometric parameters on the drag of the cavity flameholder based on the variance analysis method. Aerospace Science and Technology, 21(1):24-30. [doi:10.1016/j.ast.2011.04.009]

Huang, W., Li, S.B., Liu, J., et al., 2012b. Investigation on high angle of attack characteristics of hypersonic space vehicle. Science China Technological Sciences, 55(5): 1437-1442. [doi:10.1007/s11431-012-4760-6]

Huang, W., Wang, Z.G., Ingham, D.B., et al., 2013a. Design exploration for a single expansion ramp nozzle (SERN) using data mining. Acta Astronautica, 83:10-17. [doi:10. 1016/j.actaastro.2012.09.016]

Huang, W., Liu, J., Yan, L., et al., 2013b. Multiobjective design optimization of the performance for the cavity flameholder in supersonic flows. Aerospace Science and Technology, 30(1):246-254. [doi:10.1016/j.ast.2013.08. 009]

Huang, W., Liu, J., Jin, L., et al., 2014a. Molecular weight and injector configuration effects on the transverse injection flow field properties in supersonic flows. Aerospace Science and Technology, 32(1):94-102. [doi:10.1016/j.ast.2013.12.006]

Huang, W., Yang, J., Yan, L., 2014b. Multi-objective design optimization of the transverse gaseous jet in supersonic flows. Acta Astronautica, 93:13-22. [doi:10.1016/j. actaastro.2013.06.027]
Huang, W., Yan, L., Liu, J., et al., 2015. Drag and heat reduction mechanism in the combinational opposing jet and acoustic cavity concept for hypersonic vehicles. Aerospace Science and Technology, 42:407-414. [doi:10.1016/j.ast.2015.01.029]

Huebner, L.D., Utreja, L.J., 1993. Mach 10 bow shock behavior of forward facing nose cavity. Journal of Spacecraft and Rockets, 30(3):291-297. [doi:10.2514/3. 25513]

Jiang, Z.L., Liu, Y.F., Han, G.L., et al., 2009. Experimental demonstration of a new concept of drag reduction and thermal protection for hypersonic vehicles. Acta Mechanica Sinica, 25(3):417-419. [doi:10.1007/s10409009-0252-8]

Karagozian, A.R., 2010. Transverse jets and their control. Progress in Energy and Combustion Science, 36(5):531553. [doi:10.1016/j.pecs.2010.01.001]

Khamooshi, A., Taylor, T., Riggins, D.W., 2007. Drag and heat transfer reductions in high-speed flows. AIAA Journal, 45(10):2401-2413. [doi:10.2514/1.29062]

Knight, D., 2008. Survey of aerodynamic drag reduction at high speed by energy deposition. Journal of Propulsion and Power, 24(6):1153-1167. [doi:10.2514/1.24595]

Kulkarni, V., Reddy, K.P.J., 2008. Enhancement in counterflow drag reduction by supersonic jet in high enthalpy flows. Physics of Fluids, 20:016103. [doi:10.1063/1. 2813042]

Ladoon, D.W., Schneider, S.P., Schmisseur, J.D., 1998. Physics of resonance in a supersonic forward-facing cavity. Journal of Spacecraft and Rockets, 35(5):626632. [doi:10.2514/2.3395]

Lawrence, D., Anthony, M., Ellis, J., 1995. Experimental results on the feasibility of an aerospike for hypersonic missiles. AIAA Paper 95-0737.

Li, H.Y., Eri, Q.T., 2007. Numerical simulation of aerodynamic heating reduction due to opposing jet in supersonic flow. Proceedings of the Fifth International Conference on Fluid Mechanics, Shanghai, China.

Liu, Y.F., Jiang, Z.L., 2013. Concept of non-ablative thermal protection system for hypersonic vehicles. AIAA Journal, 51(3):584-590. [doi:10.2514/1.J051875]

Lu, H.B., Liu, W.Q., 2012a. Numerical investigation on properties of attack angle for an opposing jet thermal protection system. Chinese Physics B, 21(8):084401. [doi:10.1088/1674-1056/21/8/084401]

Lu, H.B., Liu, W.Q., 2012b. Numerical simulation in influence of forward-facing cavity on aerodynamic heating of hypersonic vehicle. Procedia Engineering, 29: 4096-4100. [doi:10.1016/j.proeng.2012.01.626]

Lu, H.B., Liu, W.Q., 2012c. Thermal protection efficiency of forward-facing cavity and opposing jet combinational configuration. Journal of Thermal Science, 21(4):342347. [doi:10.1007/s11630-012-0553-2]

Lu, H.B., Liu, W.Q., 2012d. Cooling efficiency investigation of forward-facing cavity and opposing jet combinatorial thermal protection system. Acta Physica Sinica, 61(6): 064703 (in Chinese).

Lu, H.B., Liu, W.Q., 2012e. Effect of cavity physical dimension on forward-facing cavity and opposing jet 
thermal protection system cooling efficiency. Journal of Aerospace Power, 27(12):2666-2672 (in Chinese).

Lu, H.B., Liu, W.Q., 2013. Investigation of thermal protection system by forward-facing cavity and opposing jet combinatorial configuration. Chinese Journal of Aeronautics, 26(2):287-293. [doi:10.1016/j.cja.2013.02. 005]

Lu, H.B., Liu, W.Q., 2014. Research on thermal protection mechanism of forward-facing cavity and opposing jet combinatorial thermal protection system. Heat and Mass Transfer, 50(4):449-456. [doi:10.1007/s00231-0131247-3]

Marley, C.D., Riggins, D.W., 2011. Numerical study of novel drag reduction techniques for hypersonic blunt bodies. AIAA Journal, 49(9):1871-1882. [doi:10.2514/1.J050681]

Mehta, R.C., 2000. Peak heating for reattachment of separated flow on a spiked blunt-body. Heat and Mass Transfer, 36(4):277-283. [doi:10.1007/s002310000091]

Meyer, B., Nelson, H.F., Riggins, D., 2001. Hypersonic drag and heat-transfer reduction using a forward-facing jet. Journal of Aircraft, 38(4):680-684. [doi:10.2514/2.2819]

Ohtake, K., 1998. Thermal analysis of the thermal protection system for the re-entry vehicle. Computer Methods in Applied Mechanics and Engineering, 151(3-4):301-310. [doi:10.1016/S0045-7825(97)00153-9]

Panaras, A.G., Drikakis, D., 2009. High-speed unsteady flows around spiked-blunt bodies. Journal of Fluid Mechanics, 632:69-96. [doi:10.1017/S0022112009006235]

Pezzella, G., 2012. Aerodynamic and aerothermodynamic design of future launchers preparatory program concepts. Aerospace Science and Technology, 23(1):233-249. [doi:10.1016/j.ast.2011.07.011]

Rong, Y.S., 2013. Drag reduction research in supersonic flow with opposing jet. Acta Astronautica, 91:1-7. [doi:10. 1016/j.actaastro.2013.04.015]

Rong, Y.S., Liu, W.Q., 2010. Influence of opposing jet on flow field and aerodynamic heating at nose of a reentry vehicle. Acta Aeronautica Et Astronautica Sinica, 31(8): 1552-1557 (in Chinese).

Saravanan, S., Jagadeesh, G., Reddy, K.P.J., 2009. Investigation of missile-shaped body with forward-facing cavity at Mach 8. Journal of Spacecraft and Rockets, 46(3): 577-591. [doi:10.2514/1.38914]

Shang, J.S., 2002. Plasma injection for hypersonic blunt-body drag reduction. AIAA Journal, 40(6):1178-1186. [doi:10. 2514/2.1769]

Shang, J.S., Hayes, J., Menart, J., 2002. Hypersonic flow over a blunt body with plasma injection. Journal of Spacecraft and Rockets, 39(3):367-375. [doi:10.2514/2.3835]

Silton, S.I., Goldstein, D.B., 2005. Use of an axial nose-tip cavity for delaying ablation onset in hypersonic flow. Journal of Fluid Mechanics, 528:297-321. [doi:10. 1017/S0022112004002460]

Sriram, R., Jagadeesh, G., 2009. Film cooling at hypersonic Mach numbers using forward facing array of micro-jets. International Journal of Heat and Mass Transfer, 52(1516):3654-3664. [doi:10.1016/j.ijheatmasstransfer.2009. 02.035]
Tian, T., Yan, C., 2008. Numerical simulation on opposing jet in hypersonic flow. Journal of Beijing University of Aeronautics and Astronautics, 34(1):9-12 (in Chinese).

Venukumar, B., Reddy, K.P.J., 2007. Experimental investigation of drag reduction by forward facing high speed gas jet for a large angle blunt cone at Mach 8. Sädhanā, 32:123-131.

Venukumar, B., Jagadeesh, G., Reddy, K.P.J., 2006. Counterflow drag reduction by supersonic jet for a blunt body in hypersonic flow. Physics of Fluids, 18(11): 118104. [doi:10.1063/1.2401623]

Wang, X., Pei, X., Chen, Z.M., et al., 2010. Supersonic with counter-flowing jets on drag and heat-transfer reduction. Journal of Propulsion Technology, 31(3):261-264 (in Chinese).

Wang, Z.Q., Lv, H.Q., Lei, H.S., 2010. A numerical analysis of protection of blunt leading edge from aerodynamic heating by opposed jet. Journal of Astronautics, 31(5): 1266-1271 (in Chinese).

Yadav, R., Guven, U., 2014. Aerothermodynamics of a hypersonic vehicle with a forward-facing parabolic cavity at nose. Proceedings of the Institution of Mechanical Engineers, Part G: Journal of Aerospace Engineering, 228(10):1863-1874. [doi:10.1177/0954410013498056]

Zheng, Y., Ahmed, N.A., Zhang, W., 2012. Heat dissipation using minimum counter flow jet ejection during spacecraft re-entry. Procedia Engineering, 49:271-279. [doi:10.1016/j.proeng.2012.10.137]

Zhou, C.Y., Ji, W.Y., 2014. A three-dimensional numerical investigation on drag reduction of a supersonic spherical body with an opposing jet. Proceedings of the Institution of Mechanical Engineers, Part G: Journal of Aerospace Engineering, 228(2):163-177. [doi:10.1177/09544100 12468539]

Zhou, C.Y., Ji, W.Y., Zhang, X.W., et al., 2012. Numerical investigation on counter-flow jet drag reduction of a bluff body in supersonic flow. Chinese Journal of Applied Mechanics, 29(2):159-163 (in Chinese). [doi:10. 3901/JME.2012.20.159]

Zhou, C.Y., Ji, W.Y., Zhang, X.W., et al., 2013. Numerical investigation on counter-flow jet drag reduction of a spherical body. Engineering Mechanics, 30(1):441-447 (in Chinese).

\section{中文概要}

题 目: 逆向喷流及其组合体在超声速气流中减阻防热 功效研究进展

概 要: 总结归纳国内外逆向喷流及其组合体在超声速气 流中减阻防热功效的研究进展, 并给出逆向喷流 在某些应用领域的建议, 特别是喷流的不稳定性 保护、减阻与热防护之间的权衡以及流动模态转 换的工作参数和结构参数临界点选取等。

关键词：高超声速飞行器; 减阻; 热防护; 逆向喷流; 前向凹腔; 能量沉积 